Resenhas 



\section{Interpretando a reinterpretação}

A Os livros, como às pessoas, o tempo passa de maneira desigual. É pródigo com uns, maltrata outros. Passados 21 anos de sua primeira publicação (1993), é chegada, finalmente, a versão em português da obra magna de Moishe Postone, Tempo, trabalbo e dominação social. E tal publicação é especialmente bem-vinda porque vem a lume em um momento no qual a crítica ao capitalismo parece estar de volta na agenda da teoria crítica da sociedade, retorno que é defendido de forma enfática em tal obra. ${ }^{1}$

A novidade de tal livro, e é preciso frisar esse ponto para evitar o mal-entendido, não consiste em apresentar uma interpretação mais adequada da teoria crítica madura de Marx (embora também faça isso), nem tampouco em oferecer uma atualização de tal teoria crítica de forma a tornar parte dos argumentos desenvolvidos por Marx, em sua análise do capitalismo do século XIX, relevantes para uma abordagem crítica do capitalismo do final do século XX ou mesmo do começo do XXI. Seu propósito é, antes, o de reinterpretar a obra marxiana tardia - mais especificamente $O$ capital à luz dos Grundrisse - buscando diferenciar o núcleo fundamental do capitalismo daquelas especificidades de sua forma liberal típica do século XIX, para assim se chegar ao cerne dessa formação social que estaria presente em todos os estágios pelos quais passou o capitalismo, a saber: o mercantilismo, o capitalismo liberal oitocentista, o capitalismo organizado e centrado no Estado novecentista e, por fim, o capitalismo neoliberal global contemporâneo.

\section{Ir além da teoria crítica...}

Distinguir esse nível suficientemente abstrato, ${ }^{2}$ de acordo com o autor, serve para criar a base sobre a qual é possível fazer uma teoria crítica da modernidade com relevância contemporânea. E aqui é preciso um novo esclarecimento: Postone se filia à tradição da teoria crítica da Escola de Frankfurt, e, por conseguinte, o seu objetivo principal é o de "desenvolver uma crítica política, social e cultural coerente e adequada à sociedade capitalista contemporânea por meio de uma teoria social autorreflexiva com intenção emancipadora" (p.31). Tal filiação, no entanto, não é acrítica. Na verdade, boa parte de sua argumentação tem os frankfurtianos por interlocutores, e, na mesma medida em que reconhece a influência deles, Postone esclarece que sua argumentação foi desenvolvida como uma crítica dessa tradição. Ele procura mostrar que mesmo na teoria crítica subjaz uma compreensão tradicional do marxismo, e que justamente isso fez que os frankfurtianos não conseguissem compreender a continuidade do capitalismo e de sua forma de dominação em seu estágio pós-liberal, caracterizado pelo Estado interventor (e não pelo livre mercado).

A partir da reconstrução do percurso teórico de Pollock e de Horkheimer, Postone observa que a guinada pessimista da teoria crítica não se deve apenas a fatores contextuais (a saber: o fracasso da revolução comunista e o desenvolvimento do stalinismo, a vitória do nacional-socialismo e, por fim, o caráter e a esta- 
bilização do capitalismo do pós-guerra). Pelo contrário, tal guinada seria decorrente da compreensão do novo estágio pelo qual passava o capitalismo como uma forma de capitalismo de Estado, o qual teria conseguido superar as contradições do capitalismo liberal. Isso faz que Pollock e Horkheimer adotem uma perspectiva na qual a dominação política passa a ter a primazia ante a dominação econômica, e como a ordem social com isso se torna não contraditória, ela teria conseguido se estabilizar, vindo a ser completamente administrada, integrada e unidimensional. ${ }^{3}$

Do fato de rechaçar o diagnóstico da primeira geração da teoria crítica não se segue o endosso à teoria de Jürgen Habermas. De acordo com Postone, a tentativa habermasiana de remodelar a teoria crítica padeceu também dos problemas oriundos de uma compreensão deveras limitada da teoria crítica marxiana, uma compreensão que seguiu presa a uma concepção tradicional de trabalho. A novidade de Habermas, segundo o autor, foi ter reconhecido os limites da crítica baseada no trabalho entendido como categoria trans-histórica. No entanto, em vez de contextualizar o trabalho tal como o compreendemos hoje como uma categoria moderna e capitalista, Habermas apela para outras categorias igualmente trans-históricas e descontextualizadas como base para a crítica, a saber: a interação, em um primeiro momento, e a ação comunicativa, em um segundo. Ao situar tais categorias como fundamentos normativos externos para a crítica do capitalismo, Habermas deixa de apreender tanto a contradição interna de tal forma de mediação social quanto sua dinâmica inerente, o que torna sua teoria social bastante deficitária.

\section{...se afastando ainda mais \\ do marxismo tradicional...}

Se as críticas de Postone à teoria crítica acabam por impelir o autor a retomar a própria obra tardia marxiana, sempre com o intuito de repensar o capitalismo para além de sua forma liberal típica do século XIX, tal retomada não implica nenhuma aproximação com o marxismo e com as formas em que Marx fora compreendido até então. Pelo contrário, a reinterpretação oferecida pelo autor visa oferecer uma leitura, por assim dizer, pós-marxista de Marx, uma leitura que se contrapõe frontalmente às interpretações tradicionais.

De acordo com Postone, o marxismo interpretou a teoria crítica de Marx como uma crítica da sociedade capitalista feita a partir do ponto de vista do trabalho. Isso significaria essencialmente que o trabalho não teria as suas plenas potencialidades desenvolvidas nessa ordem social, e que, por conseguinte, ele seria realizado numa sociedade socialista. Tratar-se-ia, portanto, de uma emancipação do trabalho ante as coações que impedem sua realização. No centro da crítica marxista estaria, de acordo com as interpretações tradicionais, a dominação de classe: a classe trabalhadora seria explorada pela classe capitalista, uma vez que esta segunda se apropriaria de forma indevida de parte considerável dos frutos do trabalho da primeira. O capitalismo seria entendido assim como um sistema contraditório, pois, por um lado, ele estaria baseado em um modo de produção industrial cada vez mais produtivo, mas, por outro, assentar-se-ia sobre a propriedade privada e o mercado, e isso faria que o incremento na produção não fosse desfrutado por toda a população, mas, ao contrário, somente pelos pro- 


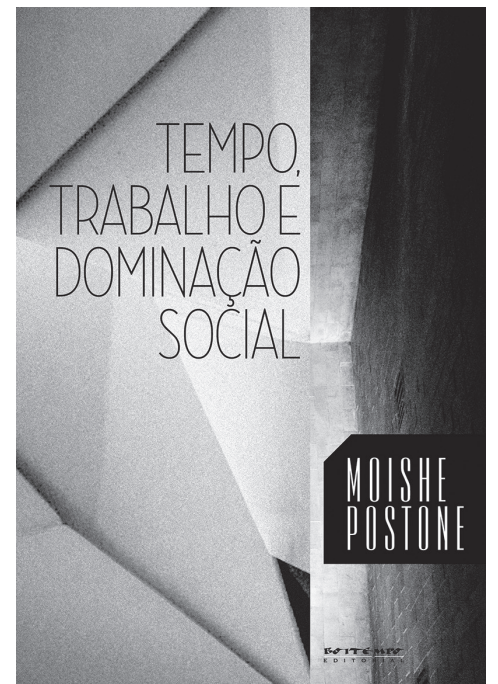

POSTONE, M. Tempo, trabalho e dominação social. São Paulo: Boitempo, 2014. 483p.

prietários. A superação do capitalismo passaria necessariamente pela tomada de consciência da totalidade da ordem social por parte dos trabalhadores, e nada mais seria do que a abolição do mercado e da propriedade privada. A sociedade emancipada seria então uma espécie de utopia do trabalho: uma comunidade na qual todos trabalham e gozam dos frutos que esse gera, sem nutrir uma classe ociosa que vive do excedente de trabalho alheio.

\section{...voltando a Marx}

Postone argumenta que a interpretação delineada acima não apenas é restritiva, como muitas vezes afirma até mesmo oposta àquilo que está na obra tardia marxiana. Destarte, ele sugere uma reinterpretação inteiramente diferente. Para começar, a teoria crítica de Marx não é feita a partir do ponto de vista do trabalho, entendido trans-historicamente, mas, pelo contrário, ela é uma crítica do trabalho. Isto é, ela compreende o trabalho não como uma cate- goria sempre existente, e sim como um construto histórico que passa a ser cada vez mais dominante como forma de mediação social. Como objeto, e não como ponto de vista, da crítica. A superação do capitalismo não seria então marcada pela realização do trabalho, mas sim pela abolição dele, ao menos na medida do possível (de acordo com o autor, o trabalho pode ser reduzido a um mínimo, mas não completamente abolido).

Com isso, Postone afirma que "a crítica de Marx da economia política é uma teoria crítica da modernidade" (p.455), uma teoria crítica que afirma que a modernidade é marcada sobretudo pela forma de dominação social do capitalismo, a qual "não consiste na dominação das pessoas por outras pessoas, mas na dominação das pessoas por estruturas sociais abstratas constituídas pelas próprias pessoas" (p.46); portanto, por uma forma de dominação abstrata, impessoal e quase objetiva. Uma forma de dominação que geralmente faz também uso da exploração, mas que em última instância independe dela. Nessa reinterpretação, a contradição fundamental do capitalismo seria intrínseca à própria constituição da mercadoria, a seus polos antagônicos de valor e valor de uso, na medida em que um constitui uma forma de riqueza abstrata ao passo que o outro forma uma riqueza material, concreta. No entanto, com o aumento das forças produtivas, o polo abstrato se torna cada vez mais supérfluo, e até mesmo um entrave para o polo concreto, mas por causa da dinâmica peculiar do capitalismo a riqueza abstrata (valor, por conseguinte, dinheiro e capital) segue sendo predominante.

A superação do capitalismo nada mais seria, assim, do que a libertação dessa forma de dominação abstrata. Tratar- 
-se-ia de uma forma de reapropriação consciente de estruturas de ação alienadas que geram e distribuem a riqueza nas sociedades modernas. Tal superação vai muito além de uma mera abolição do mercado, uma vez que findaria com as próprias categorias elementares da civilização capitalista, como o valor, a mercadoria e o dinheiro. A sociedade emancipada é vista assim como uma "forma de vida secular baseada na produção tecnologicamente avançada que não fosse moldada pela razão instrumental" (p.411) e que não visa a produção de cada vez mais valor, mas sim a redução do tempo de trabalho e o incremento máximo de tempo disponível.

\section{Nota conclusiva}

Ademais, na reinterpretação de Postone, a própria luta de classes passa a ocupar um lugar secundário, inerente ao desenvolvimento do capitalismo, em vez de principal, como o próprio fator que levaria a uma transcendência dele. Assim, o proletariado não é visto como o sujeito histórico que portaria em si as sementes da futura sociedade, mas como um produto específico dessa ordenação social. Sem dúvida isso é um trunfo da obra de Postone, uma vez que permite não apenas uma leitura realista da ordem contemporânea, na qual os trabalhadores estão, grosso modo, inteiramente integrados ao sistema capitalista, como permite justamente ir além da forma social especificamente oitocentista do capitalismo. E isso torna sua análise, apesar de seu nível deveras abstrato, pertinente para a época atual.

Se, no entanto, a teoria crítica busca mostrar as possibilidades inerentes à própria realidade (nesse caso, a possibilidade de uma libertação da dominação abstrata que levaria a um planejamento consciente da produção e a uma redução radical do tempo de trabalho) para criticar a forma existente da realidade, cabe perguntar como tais possibilidades poderiam ser realizadas. A isso não se encontra resposta na obra de Postone. Sua reinterpretação tem sucesso na apresentação de uma teoria crítica capaz de apreender o capitalismo em seu nível mais fundamental. Além disso, dá preciosas indicações para a compreensão de seu estágio contemporâneo. Mas da constatação da contradição fundamental do capitalismo que permite a crítica consequente dessa ordenação social para a possibilidade de superação de sua dinâmica intrínseca de produção de mais valor que conduz o mundo social de forma cada vez mais rápida ao abismo social e ecológico há outro abismo cuja forma de transposição segue desconhecida.

\section{Notas}

1 Infelizmente, no entanto, é preciso observar que o trabalho de tradução da obra deixou muito a desejar e em muitos aspectos: há erros grosseiros de tradução, que chegam até mesmo a inverter o significado das frases; há omissão de palavras; faltou uma revisão gramatical e ortográfica; faltou uma padronização de termos e mesmo de normas (por exemplo, o mesmo livro é citado ora com o título em inglês e ora com o título em português) etc. Até mesmo a distinção elementar entre, por um lado, "de Marx" e "marxiano/a" (of Marx, marxian) e, por outro, "marxista" (marxist) foi desrespeitada, confundindo justamente o que Postone busca contrapor.

2 Uma das críticas que se pode fazer à tese de Postone é justamente a de supor a existência de uma espécie de essência do capitalismo que estaria acima de suas manifestações temporais. Não seria talvez 
mais interessante pensar que mesmo esse cerne mais fundamental do capitalismo mudaria ao longo de seus estágios específicos?

3 Há dois problemas nessa crítica de Postone. Em primeiro lugar, ele centraliza sua análise nas obras de Pollock e Horkheimer, mas sugere que elas são válidas também para Adorno e Marcuse. Isso é muito problemático, uma vez que esses autores não aceitam a tese do capitalismo estatal, tampouco a da primazia do político. Com isso, Postone deixa de perceber que boa parte da reinterpretação da obra marxiana que ele defende já aparece, ao menos na forma de indicações, na obra tardia de Adorno (como a ideia de que a dominação é sobretudo abstrata; a crítica do trabalho - e não a partir do ponto de vista do trabalho; a superação do capitalismo como superação da totalidade etc.). Em segundo lugar, Postone parece menosprezar os fatores que ele chama de contextuais na guinada pessimista, e deixa de elencar a integração do proletariado e a intensificação da dominação por meios tanto físicos (armamentos, vigilância) quanto psíquicos (indústria cultural, antidepressivos). Com isso, ele parece estar sugerindo uma opção menos pessimista de teoria crítica, mas ele próprio não aponta para possibilidades emancipadoras presentes no horizonte atual, nem lida com os obstáculos que impedem a libertação frente a dominação abstrata que ele denuncia. Pelo contrário, contenta-se com a afirmação de que a sociedade segue sendo contraditória, o que é muito pouco para questionar tal "pessimismo".

Amaro Fleck é doutorando em Filosofia pela Universidade Federal de Santa Catarina (UFSC). @ - amarofleck@hotmail.com.

I Universidade Federal de Santa Catarina, Florianópolis/Santa Catarina, Brasil. 
